\title{
Speech Discrimination in the Elderly
}

\author{
L.P. Dickens, BA(Log) (Pretoria) \\ Department of Logopaedics, \\ University of Cape Town.
}

\begin{abstract}
The performance of 39 elderly subjects on three speech discrimination tasks, viz, CID W-22 word lists, the SPIN test and compressed SPIN sentence lists, was investigated. The effects of age and audiometric configuration on discrimination ability were examined, and age was found to significantly differentiate between subjects while audiometric configuration did not prove to be significantly variable. With the exception of the HP sentences for the SPIN and compressed speech tests, scores for all other measures differ significantly and thus would seem to assess different aspects of discrimination. The implications of these results are discussed.
\end{abstract}

\section{OPSOMMING}

Die prestasie van 39 bejaarde proefpersone op drie spraakdiskriminasietoetse, naamlik CID W-22 woordlyste, die SPIN-toets en saamgeperste SPIN-sinlyste, is ondersoek. Die invloed van ouderom en oudiometriese konfigurasie op diskriminasievermoë is bestudeer en daar is gevind dat ouderdom beduidend differensieer tussen proefpersone, terwyl oudiometriese konfigurasie nie ' $n$ beduidende variant blyk te wees nie. Met die uitsondering van die HP-sinne van die SPIN-en saamgeperste spraaktoetse, het resultate vir alle ander metings beduidend verskil en dit wil dus voorkom asof die toetse verskillende aspekte van diskriminasie ondersoek. Die implikasies van hierdie resultate word bespreek.

\section{INTRODUCTION}

The fact that hearing sensitivity deteriorates with age has been known for many years. The characteristic high-frequency nature of the loss was identified by Zwaardemaker as early as 1899 (cited by Arnst, 1985). The initial studies were mainly concerned with documenting the amount of hearing loss occurring at various frequencies (Bunch, 1929, 1931 cited by Willeford, 1978), but following the reports by Gaeth (1948, cited by Willeford, 1978) of discrimination problems experienced by the elderly, which he called "phonemic regression", interest has been focused on speech discrimination ability. The descriptive term used to denote this deterioration of auditory function that accompanies the aging process is presbycusis (Arnst, 1985, Garstecki, 1981). The more recent descriptions (Mdller, 1983; Marshall, 1981; Osterhammel and Osterhammel, 1979; and Willeford 1978) of it being a slowly progressive, bilaterally symmetrical, mildly sloping sensorineural loss, with speech discrimination skills that are poorer than would be expected for the amount of hearing loss concur with the earlier ones.

Anatomical changes due to aging have been found throughout the auditory system, and these have been extensively and unequivocally documented, e.g., Valenstein, 1981; Nadol 1981; Schuknecht, 1974, and consequently will not be dealt with in this paper. However, there is less conformity amongst the reports concerning the effect of age on auditory function, and more especially speech discrimination ability.

Many studies have compared word discrimination with sensitivity loss, and have attributed the disproportionate problems with speech perception to Central Auditory Nervous System (CANS) degeneration (e.g., Bergman, 1971; Pestalozza and Shore, 1955). A number of practical issues have complicated these investigations; thus our knowledge about the normal deterioration of hearing with age is limited (Moller, 1983) and further evaluation of the behavioural effects of presbycusis are needed (Marshall, 1981; Hayes, 1984). In investigating speech discrimination the majority of studies only measured performance at one sensation level, usually 30.40 dB SL re SRT (Marshall, 1981). However, it has been shown that maximum discrimination in the elderly may only occur at much higher levels (Kasden, 1970), thus it may be reasonable to expect that performance may have been underestimated. Generally, the early studies were concerned with monosyllabic word discrimination in ideal conditions, yet Plomp and Mimpen (1979) have established that the problems experienced by the elderly primarily manifest themselves in noisy environments. While some investigators examined the effects of noise on word and sentence identification (e.g., Jerger and Hayes, 1977; Arnst, 1985) results are conflicting and the stimuli used were not representative of everyday listening conditions. In order to define the problems experienced by the elderly, more realistic speech discrimination measures need to be used (Marshall, 1981). A measure which seems to be more appropriate for this task is the SPIN test. Kalikow, Stevens and Elliott [1977] developed this test taking into account the fact that normal adults utilise both acoustic-phonetic and linguistic-contextual cues for speech recognition, and that everyday communication occurs in a background of noise. The test examines discrimination as a function of both context and competing noise, and research has established that, as would be expected, the performance of normal hearing young adults improves when contextual cues are present and the noise level is decreased (Kalikow et al. 1977; Dickens \& Delaney, 1986). However, besides a brief preliminary report on the performance of ten elderly subjects whose scores were slightly 
depressed relative to those of younger listeners (Kalikow et al. 1977), no research (to the writer's knowledge) has concerned itself with investigating this aspect in the elderly population.

Central auditory processing can be seen as a kind of speech discrimination (Willeford, 1978), and research has suggested that reduced CANS function becomes evident when the speech is degraded in some manner. Speech can be degraded in many ways, e.g., by filtering, by time compression, by the introduction of competing messages, etc. Compressed speech provides a quick and simple means of assessing CANS function, and was first used by Calearo and Lazzaroni in 1957. These authors documented the problems that the elderly, in comparison to young listeners, experience with fast speech. Since this report much interest has been shown in this area, but subsequent studies have not all been in agreement. While Konkle, Beasley and Bess (1977) for example, confirmed the findings of Calearo and Lazzaroni, others such as Moller (1983) and Luterman, Welsh and Melrose $\{1966\}$ found no difference between young and elderly listeners, and Schmitt (1983) and Schmitt and McCroskey (1981) reported improved performance for compressed speech in a group of the elderly. A variety of procedures and materials were used in these studies. According to Beasley and Maki (1976) one needs to consider whether data from a specific study reflects upon intelligibility or comprehension. Monosyllabic stimuli would provide information pertaining to intelligibility, but may be inadequate for assessing the linguistic integrity of the central processing system, especially in cases where there is concomitant peripheral involvement (Beasley, Bratt and Rintelmann, 1980). Since this is likely to be the situation with the elderly, it would seem appropriate to use sentential stimuli for this purpose, and material such as the SPIN lists appear to be ideal, combining as they do monosyllabic and sentential features.

Finally, the effects of hearings loss, as opposed to age per se, do not appear to have been examined in much detail. Marshall (1981) suggests that peripheral problems other than sensitivity loss may underlie those problems experienced by the elderly. Dubno and Dirks $(1982,1984)$ have reported a strong relationship between audiogram shape and speech discrimination, and this needs to be investigated in relation to the elderly.

It is evident that the effects of aging on speech discrimination are not clearly understood and that the previous use of the term "phonemic regression" to explain the poor speech discrimination observed in some elderly individuals needs to be reassessed.

\section{METHODOLOGY}

\section{AIMS}

To investigate the performance of a group of elderly subjects on three speech discrimination tasks viz. CID W-22 word lists, the SPIN test, and time-compressed speech, and to examine the differential effect on performance of age as opposed to audiogram configuration.

\section{SUBJECTS}

Subjects (Ss) were selected from five old age homes located in the Cape Town area. At each of these volunteers were requested from a group of residents that had been preselected by the matron or sister-in-charge. Potential Ss were required to be over 60 years of age, English speaking, show no signs of senile dementia, and be normally active, i.e., not confined to a wheelchair or bed. While sex was not a criterion, it was hoped that a reasonable proportion of males to females would be obtained. However, there were very few male residents, and only a small percentage of these conformed to all the criteria and were willing to act as Ss. 39 Ss 178 ears| participated in the study, 36 females and 3 males. The age range was 60 to 87 years, with a mean age of 74.2 .

No Ss were excluded from the study on the basis of previous history of hearing problems or noise exposure, because the aim was to examine speech discrimination abilities in the aged population as it presents itself, as was suggested by Moller (1983). Furthermore it has been suggested that it is unrealistic to expect accurate recall of any confounding factors over a 60 year life-span or longer [Osterhammel and Osterhammel, 1979; Hayes, 1984).

\section{MATERIALS AND INSTRUMENTATION}

All speech materials were prerecorded by the same Englishspeaking South African male. The CID W-22 lists were recorded in quiet, while the SPIN lists were presented in a 12 -voice background-babble, with sentences and babble recorded on separate channels allowing for variations of the signal-to-babble $[\mathrm{S} / \mathrm{N}\}$ ratio. Lists 1 and 3 were used in the present study. The compressed speech was obtained by processing the recorded SPIN lists $\{6,7$ and 8$\}$ without the background babble through a Lexicon Varispeech Model II. The speed factor dial was set at 2 , which corresponds to a $100 \%$ compression rate. The procedure for selecting this speed factor dial setting and the collection of normative data has been described elsewhere (Dickens, 1987). List 7 was used for practice. SPIN lists were used for compressed tasks because, as previously discussed, they combine monosyllabic and sentential features, and in addition would allow for direct comparison of the effects of noise and compression on discrimination.

All audiometric testing was conducted on a Madsen Micro-5 digital audiometer, with TDH-39 earphones mounted in MX/AR supra-aural aircushions, to which a two-channel (Pioneer Stereo Tape Deck - CT-F650) tape recorder was connected. The audiometer was calibrated according to ANSI 1979 standards, and prior to each test session the VU-meters of each channel were adjusted according to the $1000 \mathrm{~Hz}$ calibration signal. Testing was conducted in a dual chamber sound-treated test suite.

\section{PROCEDURE}

Prior to assessing performance on the speech discrimination tasks, pure tone (air and bone conduction) and speech thresholds were obtained for each subject. These were necessary in order to group Ss according to audiogram configuration, and to determine presentation levels for the speech tasks. All speech measures were obtained separately for each ear under earphones.

CID W-22 lists were presented at 20,40 and $60 \mathrm{~dB}$ SL (re SRT) unless the $60 \mathrm{~dB}$ level exceeded the threshold of discomfort, in which case a lower SL was used when necessary. 
SPIN lists were presented at $40 \mathrm{~dB}$ SL (re SRT) at a $\mathrm{S} / \mathrm{N}$ ratio of $+5 \mathrm{~dB}$, as was suggested by Dickens and Delaney (1986).

Compressed speech [CSPIN] lists were also presented at 40 $\mathrm{dB}$ SL (re SRT), to allow for comparison between the various measures.

Ss were instructed to respond verbally.

\section{ANALYSIS OF RESULTS}

All scores were converted into percentages. The total high predictability (HP) and low predictability (LP) scores for both the SPIN and CSPIN tests and the maximum discrimination scores (regardless of SL) were used in the analysis. Summary statistics were calculated to describe the central tendencies. Data were subjected to two factor analyses of variance (ANOVA) with repeated measures on one factor (treatments-by-groups) to examine the difference between scores obtained for grouping according to age as opposed to audiogram configuration. Multivariate analyses and the Scheffé test were used to determine the specific comparison which accounted for the significant $F$-ratios within the interactions.

Grouping was as follows:

By age in decade:

Group I - 60 to 69 years

Group II - 70 to 79 years

Group III - 80 years and older

By audiometric configuration:

The system described by Dubno and Dirks [1982) was used.

Group A - flat; $<$ or $=20 \mathrm{~dB}$ difference in threshold from 250 to $4000 \mathrm{~Hz}$.

Group B - gradually sloping; 25 to $40 \mathrm{~dB}$ difference in threshold from 250 to $4000 \mathrm{~Hz}$, and $<30 \mathrm{~dB}$ difference in threshold between adjacent octave frequencies.

Group C - Steeply sloping; > $40 \mathrm{~dB}$ difference in threshold from 250 to $4000 \mathrm{~Hz}$ or $>30 \mathrm{~dB}$ difference between adjacent octave frequencies.

\section{RESULTS AND DISCUSSION}

Table I illustrates the mean pure tone average (PTA) for each of the three age groups. As can be seen, there is a slight increase in PTA with an increase in age. The mean age and PTA for Ss grouped according to audiometric configuration can be seen in table 2 . It is interesting to note that the groups do not differ much for mean age or PTA, and that the standard deviations for these measures are similar for all three groups.

Table 1: Mean age and PTA values for Ss grouped according to age

\begin{tabular}{|l|c|c|r|}
\hline \multirow{2}{*}{ Group I } & & PTA & Age \\
\cline { 2 - 3 } & $\overline{\mathrm{X}}$ & 25.77 & 64.91 \\
Group II & $\mathrm{SD}$ & 15.33 & 3.93 \\
& $\overline{\mathrm{X}}$ & 33.44 & 74.72 \\
Group III & $\mathrm{SD}$ & 11.81 & 3.04 \\
& $\overline{\mathrm{X}}$ & 39.90 & 83.30 \\
& $\mathrm{SD}$ & 17.66 & 2.20 \\
\hline
\end{tabular}

Table 2: Mean age and PTA values for Ss grouped according to audiogram configuration

\begin{tabular}{|l|r|r|r|}
\hline & & Age & PTA \\
\cline { 2 - 4 } Group A & $\overline{\mathrm{X}}$ & 74.40 & 33.19 \\
& $\mathrm{SD}$ & 8.10 & 13.26 \\
Group B & $\overline{\mathrm{X}}$ & 73.70 & 30.94 \\
G & $\mathrm{SD}$ & 6.65 & 13.86 \\
Group C & $\overline{\mathrm{X}}$ & 74,75 & 32.00 \\
& $\mathrm{SD}$ & 7.98 & 13.61 \\
\hline
\end{tabular}

The means and standard deviations obtained for the speech measures can be seen in table 3 . The results of the ANOVAS to examine the difference between the speech scores for the Ss grouped according to age and audiogram configuration are summarised in table 4 and 5 . These show that when Ss were grouped according to age there was a significant variance for both main effects, i.e., age and speech score, while for Ss grouped according to audiogram configuration there was a significant difference for speechscore, but not for audiogram configuration. From these results, it can be concluded that Ss scored differently on the different speech tasks, and that age rather than audiogram configuration is the critical factor which differentiates between Ss. The lack of differentiation between the audiometric groups could possibly be explained by the fact that, for some of the speech tasks, sentence stimuli were used, i.e., the SPIN and CSPIN HP items, and Dubno and Dirks (1982) report that the relationship between discrimination and audiometric configuration is weakened when sentences are used as stimuli. However, this does not explain the lack of variance between the Ss for the other speech measures, viz. the CID W.22 maximum and the LP items of the SPIN and CSPIN tests. A more likely explanation may be that the difference between the groups is qualitative rather than quantitative. Another confounding variable may be related to sample size.

Table 3: Means and standard deviations of scores obtained on the speech measures

\begin{tabular}{|lr|c|c|c|c|c|c|c|}
\hline \multicolumn{1}{|c|}{ Group } & $\begin{array}{c}\text { CID W-22 } \\
\text { Max }\end{array}$ & $\begin{array}{c}\text { SPIN } \\
\text { HP }\end{array}$ & $\begin{array}{c}\text { SPIN } \\
\text { LP }\end{array}$ & $\begin{array}{c}\text { SPIN } \\
\text { Total }\end{array}$ & $\begin{array}{c}\text { CSPIN } \\
\text { HP }\end{array}$ & $\begin{array}{c}\text { CSPIN } \\
\text { LP }\end{array}$ & $\begin{array}{c}\text { CSPIN } \\
\text { Total }\end{array}$ \\
\hline Group I & $\bar{X}$ & 91.46 & 88.38 & 45.90 & 67.14 & 86.29 & 69.71 & 78.00 \\
\{60-69| & SD & 13.14 & 8.76 & 12.50 & 8.75 & 20.30 & 23.41 & 20.00 \\
Group II & $\bar{X}$ & 88.89 & 79.54 & 37.83 & 58.69 & 80.12 & 58.91 & 70.06 \\
\{70-79| & SD & 9.47 & 14.32 & 20.20 & 14.91 & 14.91 & 17.67 & 12.61 \\
Group III & $\bar{X}$ & 72.84 & 62.35 & 18.82 & 40.59 & 60.00 & 37.18 & 48.59 \\
\{80+| & SD & 19.67 & 25.65 & 13.91 & 18.79 & 27.13 & 24.36 & 24.35 \\
All subjects & $\bar{X}$ & 85.66 & 78.08 & 35.73 & 56.90 & 77.13 & 56.90 & 67.27 \\
& SD & 15.37 & 18.83 & 19.46 & 17.31 & 22.10 & 24.10 & 21.10 \\
\hline
\end{tabular}


Table 4: ANOVA summary table showing interaction between age (A) and speech score (S)

\begin{tabular}{|c|c|c|c|c|}
\hline \multirow{4}{*}{$\begin{array}{l}\text { CID W-22 x } \\
\text { SPIN H x } \\
\text { CSPIN H }\end{array}$} & Source & df & $\mathrm{F}$ & $\mathrm{p}$ \\
\hline & A & 2 & 12.30 & .0000 \\
\hline & $S$ & 2 & 26.28 & .0000 \\
\hline & SXA & 4 & 1.81 & .1299 \\
\hline CID W-22 $\mathrm{x}$ & A & 2 & 14.84 & .0000 \\
\hline SPIN L x & $\mathrm{S}$ & 2 & 359.38 & .0000 \\
\hline CSPIN L & SXA & 4 & 2.43 & .0509 \\
\hline CID W-22 $\mathrm{x}$ & A & 2 & 15.65 & .0000 \\
\hline SPIN T $\mathrm{x}$ & S & 2 & 235.15 & .0000 \\
\hline CSPIN T & SXA & 4 & 3.19 & .0154 \\
\hline
\end{tabular}

Table 5: ANOVA summary table showing interaction between audiogram configuration $(G)$ and speech score (R).

\begin{tabular}{|l|c|c|r|c|}
\hline \multirow{2}{*}{$\begin{array}{l}\text { CID W-22 x } \\
\text { SPIN H x } \\
\text { CSPIN H }\end{array}$} & Source & $\mathrm{df}$ & $\mathrm{F}$ & $\mathrm{p}$ \\
\cline { 2 - 5 } & $\mathrm{G}$ & 2 & 1.48 & .2346 \\
\cline { 2 - 5 } $\begin{array}{l}\text { CID W-22 x } \\
\text { SPIN L x } \\
\text { CSPIN L }\end{array}$ & $\mathrm{R}$ & 2 & 22.76 & .0000 \\
\cline { 2 - 5 } & $\mathrm{G}$ & 2 & 1.95 & .1502 \\
\hline CID W-22 x & $\mathrm{R}$ & 2 & 253.86 & .0000 \\
\cline { 2 - 5 } SPIN T x & $\mathrm{RXG}$ & 4 & 1.46 & .2188 \\
\hline CSPIN T & $\mathrm{G}$ & 2 & 1.82 & .1703 \\
\cline { 2 - 6 } & $\mathrm{R}$ & 2 & 170.26 & .0000 \\
\cline { 2 - 6 } & $\mathrm{RXG}$ & 4 & 2.29 & .0632 \\
\hline
\end{tabular}

The variance in age was further investigated by means of multi-variate analysis and Scheffé post hoc comparisons. The Scheffê test results are summarised in table 6 . These indicate that the scores obtained by Group III differed significantly from those obtained by the other two groups. This difference was apparent for all the speech measures. While the mean values for the speech tasks seen in table 3 show a tendency for performance to deteriorate with increasing age for all the tests, the difference between Groups I and II was not found to be statistically significant. This performance difference could reflect a loss effect, since mean PTA scores also reflect an increase with corresponding increase in age. However, t-test computations (summarised in table 7) show that the PTA values for Group I differ significantly from Groups II and III, with no significant difference between the latter two groups. This is in contrast to the speech score differences, where Groups I and II were not statistically differentiated. The data therefore suggests a complex interaction between age and degree of loss. This is in agreement with a study by Bess and Townsend (1977) which showed that discrimination ability is dependent on both age and degree of loss, i.e., discrimination as a function of age only decreased for individuals whose PTA scores exceeded $49 \mathrm{~dB}$, while there was no age effect for Ss with PTA scores below $49 \mathrm{~dB}$. The mean PTA values for the three groups in the present study are all below $49 \mathrm{~dB}$, and a general trend for an agerelated reduction in discrimination was evident. The fact that Bess and Townsend (1977) did not see much of an age effect for Ss with smaller PTA scores could be due to their age grouping, i.e., by twenty year spans rather than by decade.

Table 6: Summary of Scheffé values showing significant age group variation for specific speech tasks.

\begin{tabular}{|l|l|l|l|l|} 
& \multicolumn{1}{|c|}{ Speech score } & $\mathrm{A}_{1}-\mathrm{A}_{2}$ & \multicolumn{1}{|c|}{$\mathrm{A}_{1}-\mathrm{A}_{3}$} & $\mathrm{~A}_{2}-\mathrm{A}_{3}$ \\
\cline { 2 - 5 } $\mathrm{A}_{1}=60-69$ & Max. CID W-22 & 1.2 & $4.215^{++}$ & $3.487^{++}$ \\
\cline { 2 - 5 } $\mathrm{A}_{2}=70-79$ & SPIN H & 1.6741 & $4.8738^{+++}$ & $3.7609^{++}$ \\
\cline { 2 - 6 } $\mathrm{A}_{3}=80+$ & CSPIN H & 1.1064 & $4.0337^{+++}$ & $3.3736^{++}$ \\
\cline { 2 - 6 } & SPIN L & 1.7360 & $4.8347^{+++}$ & $3.6602^{++}$ \\
\cline { 2 - 6 } & CSPIN L & 1.8283 & $4.7118^{+++}$ & $3.4397^{++}$ \\
\cline { 2 - 6 } & SPIN T & 1.952 & $5.675^{+++}$ & 4.448 \\
\cline { 2 - 6 } & CSPIN T & 1.5613 & $4.948^{+++}$ & $3.9365^{+++}$ \\
\hline
\end{tabular}

F CRIT 2,68: $2.501: \mathrm{p}<0.05+$

$3.138: \mathrm{p}<0.01++$

$3.908: \mathrm{p}<0.001+++$

Table 7: Summary of T-test values showing significant PTA difference

\begin{tabular}{|l|l|}
\hline Comparison & T-value \\
\hline Groups I X II & $2.085+$ \\
Groups II X III & 1.822 \\
Groups I X III & $2.776++$ \\
\hline
\end{tabular}

+ p 0.05

$++\mathrm{p} \quad 0.01$

The present results indicate that a significant age $X$ degree of loss interaction occurs when the loss exceeds $33 \mathrm{~dB}$ (mean! PTA value for Group II], and that the trend for scores to deteriorate with increasing age is also apparent for smaller PTA values.

The distribution of the CID W-22 maximum scores for each group and the entire sample can be seen in figure 1. This shows that the majority of Ss $(56 \%)$ had discrimination scores which were better than $91 \%$, which can be seen to refute the statement that disproportionately poor speech discrimination scores are a general feature of age-related hearing loss. This supports Moller's (1981, cited by Moller, 1983) finding, although the present proportion is slightly lower than Moller's. The reason for this may be twofold; Moller only used 70 year old Ss (reassessed at 75), and their average loss was less severe.

In addition to the quantitative difference between Groups III, and I and II, figure 1 also illustrates the qualitative differences (in terms of general distribution\}. Groups I and II fol- 


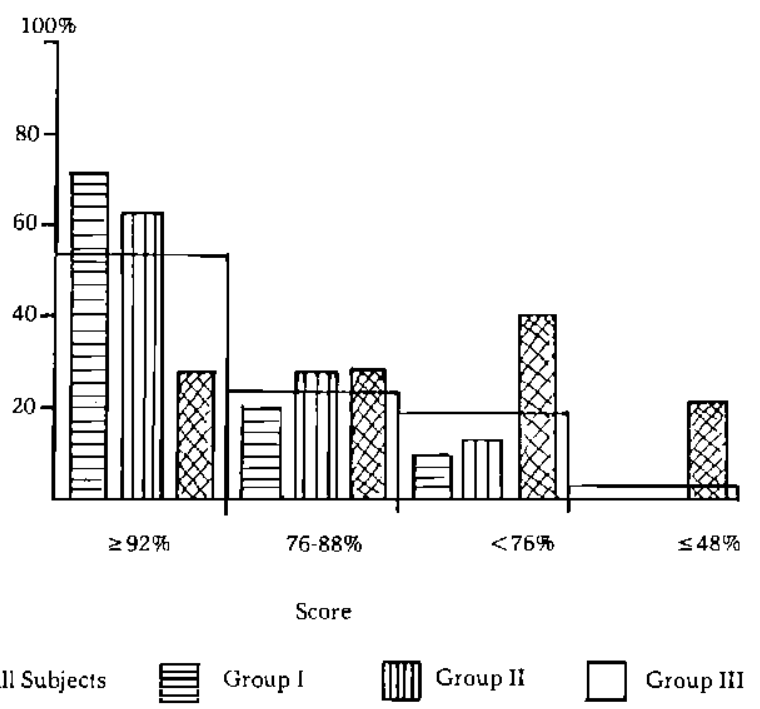

Figure 1. CID W-22 maximum discrimination scores

low a similar trend (which is the trend shown by the entire sample), i.e., the majority of Ss show good discrimination, with only $9 \%$ and $14 \%$ respectively, obtaining scores below $76 \%$. The pattern for Group III differs, showing a flatter distribution curve with the majority $(37 \%)$ having scores below $76 \%$. This further illustrates the complex interactive effects of age and degree of loss on discrimination.
Examination of the SPIN scores shows that there is the expected HP and LP separation, and that the scores are reduced in relation to those reported for normal hearing young Ss (Dickens and Delaney, 1986). While both HP and LP scores are reduced, the reduction is much larger for the LP items, and this becomes more pronounced with increa. sing age. This was also seen for the compressed speech. Scores collected from 30 normal hearing $S s$ were: total equals 90.00 (3.58), HP $=97.09$ (3.14), and LP $=82.91$ (6.95) (Dickens, 1987). An interesting finding is that the standard deviations for all groups tend to be larger for compressed speech. This would seem to support Mbller's contention that in a "non-clinical" group of elderly, there are those individuals with well-preserved central auditory function as well as those with presumable central auditory problems.

The results of the Scheffẽ computations to investigate significant speech score variation within the different age groups can be seen in table 8 . For Group I there was no significant difference between scores obtained for the CID W-22, the SPIN HP and the CSPIN HP procedures, and for both Groups II and III there was no difference between the SPIN HP and CSPIN HP scores. For all the other measures the speech score variation was found to be significant within all three age groups, indicating that the tests assess different aspects of auditory discrimination.

The lack of significant difference for the HP measures for all Ss, regardless of age or audiometric configuration, is interes-

Table 8: Summary table of Scheffé values showing significant speech score variation within age groups.

\begin{tabular}{|c|c|c|c|c|}
\hline \multirow{4}{*}{$\begin{array}{l}\mathrm{S}_{1}=\text { CIS } \mathrm{W}-22 \text { max. } \\
\mathrm{S}_{2}=\text { SPIN } \mathrm{H} \\
\mathrm{S}_{3}=\text { CSPIN } \mathrm{H}\end{array}$} & Groups & $S_{1}-S_{2}$ & $S_{1}-S_{3}$ & $S_{2}-S_{3}$ \\
\hline & $\begin{array}{c}A_{1} \\
(60-69)\end{array}$ & 1.6829 & 2.4219 & .0738 \\
\hline & $\begin{array}{c}\mathbf{A}_{\mathbf{2}} \\
(70-79)\end{array}$ & $3.701^{++}$ & $3.9755^{+++}$ & .2703 \\
\hline & $\begin{array}{c}A_{3} \\
{[79+]} \\
\end{array}$ & $4.4917^{+++}$ & $5.2393^{+++}$ & .7476 \\
\hline \multirow{4}{*}{$\begin{array}{l}\mathrm{S}_{1}=\text { CIS W }-22 \max \\
\mathrm{S}_{2}=\text { SPIN L } \\
\mathrm{S}_{3}=\text { CSPIN L }\end{array}$} & Groups & $S_{1}-S_{2}$ & $S_{1}-S_{3}$ & \multirow{2}{*}{$\begin{array}{l}S_{2}-S_{3} \\
6.8764^{+++}\end{array}$} \\
\hline & $\begin{array}{c}A_{1} \\
(60-69)\end{array}$ & $13.643^{+++}$ & $6.7667^{+++}$ & \\
\hline & $\begin{array}{c}\mathbf{A}_{2} \\
(70-79)\end{array}$ & $18.647^{+++}$ & $10.925^{+++}$ & $7.7215^{+++}$ \\
\hline & $\begin{array}{c}\mathrm{A}_{3} \\
(79+)\end{array}$ & $14.9788^{+++}$ & $10.2084^{t++}$ & $4.7703^{+++}$ \\
\hline \multirow{4}{*}{$\begin{array}{l}\mathrm{S}_{1}=\text { CIS W-22 max. } \\
\mathrm{S}_{2}=\text { SPIN T } \\
\mathrm{S}_{3}=\text { CSPIN T }\end{array}$} & Groups & $S_{1}-S_{2}$ & $S_{1}-S_{3}$ & $S_{2}-S_{3}$ \\
\hline & $\begin{array}{c}A_{1} \\
\{60-69\}\end{array}$ & \multirow{2}{*}{$\begin{array}{r}10.198^{+++} \\
14.721^{+++}\end{array}$} & $5.938^{+++}$ & \multirow{2}{*}{$\begin{array}{l}4.2596^{+++} \\
5.364^{+++}\end{array}$} \\
\hline & $\begin{array}{c}\mathbf{A}_{2} \\
(70-79)\end{array}$ & & $9.3587^{+++}$ & \\
\hline & $\begin{array}{c}\mathrm{A}_{3} \\
(79+)\end{array}$ & $13.368^{t++}$ & $9.839^{+++}$ & $2.823^{+}$ \\
\hline
\end{tabular}

F CRIT 2,68: $2.501: \mathrm{p}<0.05+$

$3.138: \mathrm{p}<0.01++$

$3.908: \mathrm{p}<0.001+++$ 
ting. Introduction of noise and compression did not have a differential effect on HP performance, while for the LP sentences the two conditions were differentiated. Thus, the important feature seems to be context, which apparently helps to overcome the distortion, regardless of the nature of the distortion. This has important implications for rehabilitation with the elderly hearing impaired client, in that more emphasis should be placed on teaching him to utilise contextual information in order to overcome problems which he experiences in the less than ideal type of communicative situation.

It would also be interesting to investigate the performance of different groups of Ss, including those with CANS disorders, to determine whether any demonstrate an HP discrepancy for the SPIN and CSPIN tests, and thus whether this could be used diagnostically.

For all Ss the scores obtained for the CID W-22 lists were the highest, with CSPIN and SPIN following in that order. Very often the elderly specifically complain of problems in understanding speech in noise, yet this aspect is not routinely investigated. The present results indicate that the Ss perform differently in noise and quiet, supporting the research by Plomp and Mimpen (1979), which showed that Ss with the same hearing loss for speech in quiet may differ in their performance in noise, and that this could not really be predicted from the performance in quiet. The fact that the scores for the speech measures in quiet and noise differ significantly suggests that different aspects of auditory function are being measured. A study by Festen and Plomp [1983) provides support for this. They investigated the relationship between various auditory functions in hearing impaired individuals, and concluded that hearing loss for speech in quiet is determined by audiometric loss, while hearing loss for speech in noise is governed by frequency resolution abilities.

If different aspects of auditory function are being measured, as this and previous research suggests, it is necessary to include, in the routine audiologic battery, a test which evaluates discrimination in noise.

All the Ss performed more poorly in the SPIN than on the CSPIN test. The reduction in performance on both the CSPIN and the SPIN tests could be seen as evidence of central processing problems \{i.e., compressed speech is generally considered to be sensitive to disorders ir the central auditory nervous system, and all Ss performed more poorly on the SPIN). It could be argued that the noise element in the SPIN test reduces the redundancy of the speech signal to a greater degree than the compression in the CSPIN test and, that it it is therefore tapping more subtle CANS disorders. However, the more likely explanation is that reduced performance on the SPIN is the result of peripheral processing problems, and that the reduction in performance on the CSPIN may also be due to the peripheral involvement rather than central problems. The study of Plomp and Mimpen [1979] which investigated SRT for sentences as function of age and noise appears to support this, i.e., they found that for Ss up until about 90 years of age, the critical variable in hearing loss for speech is deterioration in auditory processing rather than in central processing.

In conclusion, it is evident that, except for the HP sections of the SPIN and CSPIN tests, all other measures appear to be assessing different aspects of auditory discrimination, and that age rather than audiometric configuration is the distinguishing factor. As a group the elderly perform fairly well on conventional speech discrimination tasks (i.e., CID W-22 lists in quiet) but this does not reflect the problem that they may have in different situations. Since the most common complaint of the elderly patient in a clinic is the difficulty that he experiences with speech in noisy situations it is recommended that a speech in noise test be administered routinely. It may be advisable to administer both the SPIN and CSPIN tests, since this may provide potentially important diagnostic and rehabilitative information concerning the differential effect of distortion. At this stage it is not clear whether the problems that the elderly experience with compressed speech and especially with speech in noise is a reflection of CANS disorder or breakdown in peripheral auditory processing. Before any final comment can be made concerning the question of central processing problems in the elderly, further research needs to be conducted, firstly, to determine the sensitivity of the SPIN and CSPIN in detecting CANS disorders in patients with documented lesions and, secondly, to establish the influence of peripheral sensitivity loss on young listeners' performance on these tests.

\section{REFERENCES}

Arnst, D.J. Presbycusis. In J. Katz (Ed.) Handbook of Clinical Audiology, 3rd edition Baltimore: Williams \& Wilkins, 1985.

Beasley, D.S. \& Maki, J.E. Time and Frequency Altered Speech. In N.J. Lass (Ed.) Contemporary Issues in Experimental Phonetics. New York: Academic Press, 1976.

Beasley D.S., Bratt, G. \& Rintelmann, W. Intelligibility of TimeCompressed Sentential Stimuli. J. Speech Hear. Res., 23, 722739, 1980.

Bergman, M. Hearing and Aging, Audiology 10, 164-171, 1971

Bergman, M. Central Auditory Disorders. In R. Hinchcliffe (Ed.) Hearing and Balance in the Elderly. New York: Churchill Livingstone, 1983.

Bess, F.H. \& Townsend, T.H. Word Discrimination for Listeners with Flat Sensorineural Hearing Losses. J. Speech Hear. Disord., 42, 232-237, 1977.

Calearo, C. \& Lazzaroni, A. Speech Intelligibility in Relation to the Speed of the Message, Laryngoscope, 67, 410-419, 1957.

Dickens, L.P. \& Delaney, C.M. An Evaluation of the Speech Perception in Noise Test. S.A. J. Comm. Dis., 33, 78-80, 1986.

Dickens, L.P. Audiological Correlates of Aging. Unpublished Master's Dissertation, University of the Witwatersrand, 1987.

Dubno, J. \& Dirks, D. Evaluation of Hearing Impaired Listeners using a Nonsense-Syllable Test. I. Test Reliability. J. Speech Hear. Res., 25, 135-141, 1982.

Dirks, D.D. \& Dubno, J.R. Speech Audiometry. In J. Jerger (Ed. Hearing Disorders in Adults: Current Trends. San Diego: College-Hill Press, 1984.

Festen, J.M. \& Plomp, R. Relations between Auditory Functions in Impaired Hearing. J. Acous. Soc. Am., 73/2, 652-662, 1983

Garstecki, D.C. Aural Rehabilitation for the Aging Adult. In D. Beasley \& G. Davis (Eds.) Aging: Communication Processes and Disorders. New York: Grune \& Stratton, 1981.

Hayes, D. Hearing Problems in Aging. In J. Jerger (Ed.) Hearing Disorders in Adults: Current Trends. San Diego: College-Hill Press, 1984.

Jerger, J. \& Hayes, D. Diagnostic Speech Audiometry. Arch. Otolaryngol, 102, 216-222, 1977.

Kalikow, D.N., Stevens, K.N. \& Elliot, L.L. Development of a Test of Speech Intelligibility in Noise Using Sentence Materials with Controlled word Predictability. J. Acous, Soc. Am., 61,5 $1337-1351,1977$

Kasden, S.D. Speech Discrimination in Two Age Groups Matched for Hearing Loss. J. Aud. Res., 10, 210-212, 1970.

Konkle, D.F., Beasley, D.S. \& Bess, F.H. Intelligibility of TimeAltered Speech in Relation to Chronological Aging. $J$. Speech Hear. Res., 20, 108-115, 1977. 
Luterman, D.M. Welsh, C.L. \& Melrose, J. Responses of Aged Males to Time-Altered Speech Stimuli. J. Speech. Res., 9, 226230, 1966.

Marshall, L. Auditory Processing in Aging Listeners. J. Speech Hear. Disord, 46, 226-240, 1981.

Møller, M.B. Changes in Hearing Measures with Increasing Age. In $\mathrm{R}$. Hinchcliffe (Ed.) Hearing and Balance in the Elderly. New York: Churchill Livingstone, 1983.

Nadol. J.B. The Aging Peripheral Hearing Mechanism. In D.S. Beasley \& G.A. Davis (Eds.) Aging: Communication Processes and Disorders. New York: Grune \& Stratton, 1981.

Osterhammel, D. \& Osterhammel, P. High Frequency and Audiometry: Age and Sex Variation. Scand. Audiol. 8, 73-81, 1979.

Pestalozza, G. \& Shore, I. Clinical Evaluation of Presbycusis on the Basis of Different Tests of Auditory Function. Lanyngoscope, 65, 1136-1163, 1955.

Plomp، R. \& Mimpen, A.R. Speech-Reception Threshold for Senten- ces as a Function of Age and Noise Level. J. Acous. Soc. Am., $66,1333-1343,1979$.

Schmitt, J.F. \& McCroskey, R.L. Sentence Comprehension in Elderly Listeners: The Factor of Rate. J. Gerontology, 36, 441-445, 1981.

Schmitt, J.F. The Effects of Time Compression and Time Expansion on Passage Comprehension by the Elderly. J. Speech Hear. Res., 26,373-377, 1983.

Schuknecht, H.F. Pathology of the Ear. Campbride Mass: Harvard University Press, 1974.

Valenstein, E. Age-Related Changes in the Human Central Nervous System. In D.S. Beasley \& G.A. Davis (Eds.) Aging: Communication Processes and Disorders. New York: Grune \& Stratton, 1981.

Willeford, J.A. The Geriatric Patient. In D. Rose (Ed.) Audiological Assessment, 2nd Ed., New Yersey: Prentice-Hall, 1978. 


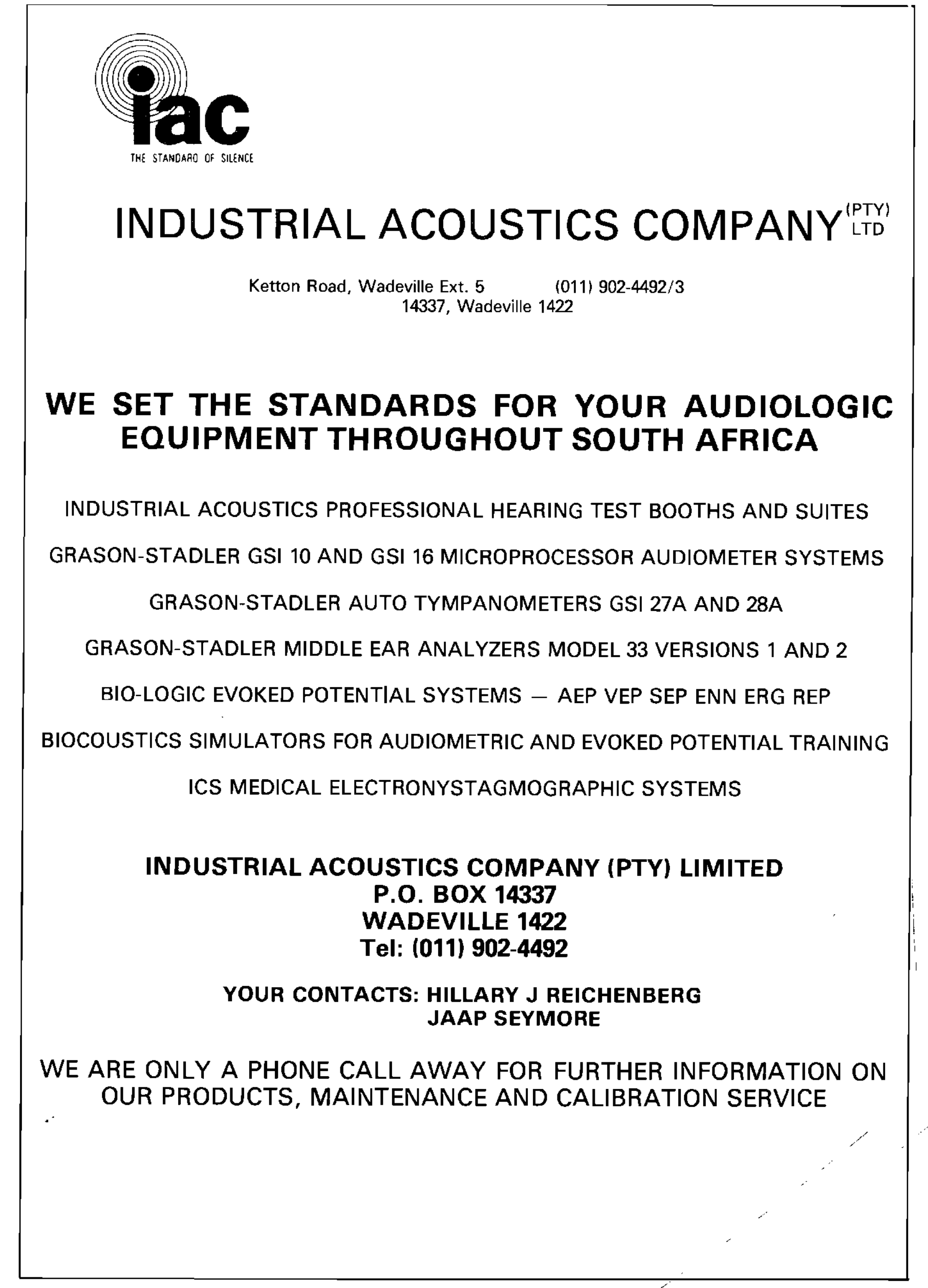

